\title{
Effect of Extending the Original Eligibility Criteria for the CROSS Neoadjuvant Chemoradiotherapy on Toxicity and Survival in Esophageal Cancer
}

\author{
E. C. de Heer, BSc ${ }^{1,2}$, J. B. Hulshoff, MD' ${ }^{1}$, D. Klerk ${ }^{2}$, J. G. M. Burgerhof, MSc ${ }^{3}$, D. J. A. de Groot, MD, PhD ${ }^{2}$, \\ J. Th. M. Plukker, MD, $\mathbf{P h D}^{1}$, and G. A. P. Hospers, $\mathrm{MD}, \mathbf{P h D}^{2}$ \\ ${ }^{1}$ Department of Surgical Oncology, University of Groningen, University Medical Center Groningen, Groningen, The \\ Netherlands; ${ }^{2}$ Department of Medical Oncology, University Medical Center Groningen, Groningen, The Netherlands; \\ ${ }^{3}$ Department of Epidemiology, University of Groningen, Groningen, The Netherlands
}

\begin{abstract}
Background. Patients with curable esophageal cancer (EC) who proceed beyond the original Chemoradiotherapy for Oesophageal Cancer Followed by Surgery Study (CROSS) eligibility criteria are also treated with neoadjuvant chemoradiotherapy (nCRT). This study assessed the effect that extending the CROSS eligibility criteria for nCRT has on treatment-related toxicity and overall survival (OS) in EC.

Methods. The study enrolled 161 patients with locally advanced EC (T1N1-3/T2-4aN0-3/M0) treated with the CROSS schedule followed by esophagectomy. Group 1 consisted of 89 patients who met the CROSS criteria, and group 2 consisted of 72 patients who met the extended eligibility criteria, i.e. a tumor length greater than $8 \mathrm{~cm}$ $(n=24)$, more than $10 \%$ weight loss $(n=35)$, more than $2-4 \mathrm{~cm}$ extension in the stomach $(n=21)$, celiac lymph node metastasis $(n=13)$, and/or age over 75 years
\end{abstract}

E. C. de Heer and J. B. Hulshoff contributed equally to the manuscript.

E. C. de Heer and J. B. Hulshoff had control over data.

Electronic supplementary material The online version of this article (doi:10.1245/s10434-017-5797-3) contains supplementary material, which is available to authorized users.

(C) The Author(s) 2017. This article is published with open access at Springerlink.com

First Received: 13 September 2016;

Published Online: 10 February 2017

G. A. P. Hospers, MD, PhD

e-mail: g.a.p.hospers@umcg.nl $(n=2)$. The study assessed the differences in nCRT-associated toxicity [National Cancer Institute's Common Terminology Criteria for Adverse Events (CTCAE) grade $\geq 3$ ] and 90-day postoperative mortality. Moreover, the prognostic value for OS was assessed with multivariate Cox regression analysis.

Results. No difference was found in nCRT-associated toxicity $(P=0.117), \quad$ postoperative complications $(P=0.783)$, and 90 -day mortality $(P=0.492)$. The OS differed significantly $(P=0.004)$, with a median of 37.3 months $\quad[95 \%$ confidence interval (CI), 10.4-64.2 months] for group 1 and 17.2 months (95\% CI 13.8-20.7 months) for group 2. Pathologic $\mathrm{N}$ stage $(P=0.023)$, pathologic $\mathrm{T}$ stage $(P=0.043)$, and group 2 $(P=0.008)$ were independent prognostic factors for OS. Conclusions. Extension of the CROSS study eligibility criteria for nCRT did not affect nCRT-associated toxicity, postoperative complications, and postoperative mortality, but was prognostic for OS.

Neoadjuvant chemoradiotherapy (nCRT) according to the Chemoradiotherapy for Oesophageal Cancer Followed by Surgery Study (CROSS) schedule (carboplatin/paclitaxel and 41.4 Gy radiotherapy) followed by a radical surgical resection is the gold standard for locally advanced esophageal cancer (EC) in the Netherlands. ${ }^{1}$ This nCRT scheme increased the 5-year overall survival (OS) by 10-13\% while the postoperative complication rate did not increase. ${ }^{1,2}$

Patients with a potentially curative resectable EC who do not meet the original CROSS study inclusion criteria are currently also treated with nCRT, i.e. including patients aged over 75 years and those with a tumor length $>8 \mathrm{~cm}$, a tumor that extends $>2-4 \mathrm{~cm}$ into the gastric cardia, and/or 
$>10 \%$ body weight loss. Moreover, the original CROSS study excluded patients with celiac lymph node metastases because these nodes were previously classified as distant metastases (M1a) in the American Joint Committee on Cancer (AJCC) TNM 6th edition. ${ }^{3}$ The currently used 7th edition of the AJCC TNM classifies celiac node involvement as regional metastasis (N1-3), and these patients are consequently treated with nCRT. ${ }^{4}$

Besides a small Dutch study, which found that the extended inclusion criteria tumor length $>8 \mathrm{~cm}$ and age over 75 years did not influence the complication rate, no study has assessed the influence of extension of all CROSS eligibility criteria for nCRT on toxicity and survival. ${ }^{5}$ This study was designed to assess the effect of extended eligibility criteria for treatment with nCRT on the toxicity and mortality ( $<90$ days posttreatment) of EC patients. Furthermore, we assessed the difference in disease-free survival (DFS) and OS between patients that met the original CROSS study inclusion criteria and patients in the extended inclusion group.

\section{PATIENTS AND METHODS}

\section{Patients}

Data for this retrospective study were obtained from a prospectively maintained database and the study was conducted according to the national guidelines and the rules approved by the local ethics board. All patients with locally advanced EC (TNM7: T1N1-3/T2-4aN0-3/M0) who underwent nCRT according to the CROSS schedule followed by surgery between 2005 and 2015 at the University Medical Center Groningen were eligible for inclusion.

All patients included in the study had a histologically proven adenocarcinoma or squamous cell carcinoma of the esophagus or esophagogastric junction. In addition, the patients had an adequate hematologic, renal, hepatic, and pulmonary function, together with a World Health Organization (WHO) performance status of 2 or lower.

Based on the aforementioned criteria, 177 patients were eligible for inclusion. A total of 16 patients were excluded because of concurrent malignancies $(n=3)$, previous malignancies within 5 years before treatment $(n=3)$, missing blood values $(n=7)$, progressive disease due to distant metastases present on the restaging PET/CT $(n=2)$, or a prolonged interval ( $>6$ months) between nCRT and surgery $(n=1)$. Consequently, 161 patients were included in the study.

\section{METHODS}

The patients were divided in two groups. Group 1 consisted of 89 patients who met the original CROSS study inclusion criteria, and group 2 consisted of 72 patients with the extended nCRT criteria. Group 2 included 24 patients with a tumor longer than $8 \mathrm{~cm}, 35$ patients with more than $10 \%$ weight loss, 21 patients with more than $2-4 \mathrm{~cm}$ tumor extension in the gastric cardia, 13 patients with celiac lymph node metastasis, and 2 patients older than 75 years.

The primary objective was to assess the difference in nCRT-related toxicity (grade $\geq 3$ ) between group 1 and 2 . All treatment complications and severity were measured according to the National Cancer Institute's Common Terminology Criteria for Adverse Events (CTCAE) version 4.0 grading scale. ${ }^{6}$ The secondary outcomes were the difference in postoperative complications, postoperative mortality (30- and 90-day rates), DFS, and OS. DFS was defined as the time between the start of nCRT and the date of tumor recurrence and OS as the time between the start of nCRT and the date of death or last follow-up.

In addition, we compared OS of the extended CROSS group with a reference dCRT group using a multivariate Cox regression analysis containing all confounders (gender, cTN stage, tumor location, tumor length, histology, and age).

\section{Staging}

All patients were staged with endoscopic ultrasonography combined with a fine-needle aspiration biopsy when indicated, computed tomography (CT) of the chest and abdomen, and 18-F-fluorodeoxyglucose (FDG) positron emission tomography (PET) or integrated FDG-PET/CT. When indicated, additional imaging was performed. Patients were staged according to the 7 th edition of the tumor-node-metastasis (TNM) classification. ${ }^{4}$

\section{Treatment}

All patients received nCRT according to the CROSS schedule, consisting of five weekly intravenous administrations of carboplatin [area under the curve (AUC) $2 \mathrm{mg} /$ $\mathrm{ml} / \mathrm{min}$ ] and paclitaxel $\left(50 \mathrm{mg} / \mathrm{m}^{2}\right)$, as well as concurrent external beam radiotherapy (41.4 Gy/23 fractions) 5 days per week. ${ }^{1,2}$ After nCRT, either a radical transthoracic or minimally invasive esophagectomy was performed, with en bloc dissection of mediastinal and abdominal lymph nodes. Definitive chemoradiotherapy (dCRT) consisted of either carboplatin/paclitaxel (AUC 2 and $50 \mathrm{mg} / \mathrm{m}^{2}$ ) or cisplatin and fluorouracil (Cis-5FU, $75 \mathrm{mg} / \mathrm{m}^{2}$ and $1 \mathrm{~g} / \mathrm{m}^{2}$ ) combined with radiotherapy (40-60 Gy in 30 fractions).

\section{Pathology}

Resected specimens were pathologically assessed according to a standard protocol on histologic subtype, 
TABLE 1 Patient and tumor characteristics of group 1 (CROSS inclusion criteria) and group 2 (not eligible for CROSS)

\begin{tabular}{|c|c|c|c|}
\hline & $\begin{array}{l}\text { Group 1 } \\
(n=89) \\
n(\%)\end{array}$ & $\begin{array}{l}\text { Group } 2 \\
(n=72) \\
n(\%)\end{array}$ & $P$ value \\
\hline Male & $71(79.8)$ & $57(79.2)$ & $0.924^{\mathrm{a}}$ \\
\hline Age (years), median (IQR) & $63(58-67)$ & $64(57-69)$ & $0.299^{\mathrm{b}}$ \\
\hline WHO/ECOG performance status & & & $0.843^{\mathrm{a}}$ \\
\hline $0-1$ & $85(95.5)$ & $64(88.9)$ & \\
\hline 2 & $0(0.0)$ & $0(0.0)$ & \\
\hline Missing & $4(4.5)$ & $8(11.1)$ & \\
\hline Comorbidities total & $44(49.4)$ & $38(52.8)$ & $0.673^{\mathrm{a}}$ \\
\hline Cardiovascular & $34(38.2)$ & $28(38.9)$ & $0.798^{\mathrm{a}}$ \\
\hline Pulmonary & $3(3.4)$ & $1(1.4)$ & \\
\hline Cardiovascular and pulmonary & $5(5.6)$ & $6(8.3)$ & \\
\hline Other & $2(2.2)$ & $3(4.2)$ & \\
\hline No comorbidities & $45(50.6)$ & $34(47.2)$ & \\
\hline Histology & & & $0.095^{\mathrm{a}}$ \\
\hline Adenocarcinoma & $79(88.8)$ & $57(79.2)$ & \\
\hline Squamous cell carcinoma & $10(11.2)$ & $15(20.8)$ & \\
\hline \multicolumn{4}{|l|}{ Tumor location } \\
\hline Middle esophagus & $7(7.9)$ & $5(6.9)$ & $0.005^{\mathrm{a}}$ \\
\hline Distal esophagus & $76(85.4)$ & $49(68.1)$ & \\
\hline GEJ & $6(6.7)$ & $18(25.0)$ & \\
\hline Tumor length $(\mathrm{cm})$, median (IQR) & $5.0(3.0-6.0)$ & $6.5(5.0-9.0)$ & $0.000^{\mathrm{b}}$ \\
\hline cT stage & & & $0.000^{\mathrm{a}}$ \\
\hline $\mathrm{T} 1$ & $0(0.0)$ & $2(2.8)$ & \\
\hline $\mathrm{T} 2$ & $25(28.1)$ & $5(6.9)$ & \\
\hline $\mathrm{T} 3$ & $63(70.8)$ & $56(77.8)$ & \\
\hline $\mathrm{T} 4 \mathrm{a}$ & $1(1.1)$ & $9(12.5)$ & \\
\hline $\mathrm{cN}$ stage & & & $0.024^{\mathrm{a}}$ \\
\hline No & $22(24.7)$ & $7(9.7)$ & \\
\hline N1 & $38(42.7)$ & $30(41.7)$ & \\
\hline $\mathrm{N} 2$ & $27(30.3)$ & $29(40.3)$ & \\
\hline $\mathrm{N} 3$ & $2(2.2)$ & $6(8.3)$ & \\
\hline ypT stage & & & $0.525^{\mathrm{a}}$ \\
\hline $\mathrm{CR}$ & $15(16.9)$ & $13(18.1)$ & \\
\hline $\mathrm{T} 0$ & $4(4.5)$ & $2(2.8)$ & \\
\hline $\mathrm{T} 1$ & $17(19.1)$ & $8(11.1)$ & \\
\hline $\mathrm{T} 2$ & $11(12.4)$ & $9(12.5)$ & \\
\hline $\mathrm{T} 3$ & $42(47.2)$ & $40(55.6)$ & \\
\hline ypN stage & & & $0.706^{\mathrm{a}}$ \\
\hline N0 & $57(64.0)$ & $44(61.1)$ & \\
\hline N1 & $18(20.2)$ & $16(22.2)$ & \\
\hline $\mathrm{N} 2$ & $11(12.4)$ & $7(9.7)$ & \\
\hline $\mathrm{N} 3$ & $3(3.4)$ & $5(6.9)$ & \\
\hline Perineural growth & $15(16.9)$ & $18(25.0)$ & $0.204^{\mathrm{a}}$ \\
\hline Lymphangio-invasion & $14(15.7)$ & $19(26.4)$ & $0.097^{\mathrm{a}}$ \\
\hline $\mathrm{LN}$ ratio $(>0.2 \mathrm{LN}+)$ & $12(13.5)$ & $11(15.3)$ & $0.747^{\mathrm{a}}$ \\
\hline
\end{tabular}


TABLE 1 continued

\begin{tabular}{|c|c|c|c|}
\hline & $\begin{array}{l}\text { Group 1 } \\
(n=89) \\
n(\%)\end{array}$ & $\begin{array}{l}\text { Group } 2 \\
(n=72) \\
n(\%)\end{array}$ & $P$ value \\
\hline Follow-up (months), median (IQR) & $23.2(11.8-52.9)$ & $16.2(9.2-40.3)$ & $0.037^{\mathrm{b}}$ \\
\hline
\end{tabular}

radicality of the resection margins (proximal, distal, and circumferential), pathologic $\mathrm{T}$ (ypT) stage, pathologic lymph node (ypN) stage, tumor location, perineural growth, and lymphangio-invasion.

\section{Follow-up Evaluation}

According to the standard protocol, patients were seen every 3 months during the first year, every 4 and 6 months during the second and third year, and subsequently once every succeeding year until 10 years after treatment. During the follow-up, tumor recurrence and/or cause of death was accurately described. Tumor recurrence was proven either pathologically or radiologically.

\section{Statistical Analysis}

Differences in patient characteristics and complications were assessed using the Chi square test or the likelihood ratio test for categorical variables and the Mann-Whitney $U$ test for non-normally distributed variables.

Kaplan-Meier curves were used to display the DFS and OS. Univariate Cox regression analysis was performed on all possible prognostic factors for both DFS and OS. All factors with a $P$ value lower than 0.10 in the univariate Cox regression analysis were included in the multivariate Cox regression analysis. A $P$ value lower than 0.05 was considered statistically significant. All statistical analyses were performed with IBM SPSS Statistics for Windows, version 22.0 (IBM Corp., Armonk, NY, USA).

\section{RESULTS}

\section{Patients' Characteristics}

The characteristics of the patients are summarized in Table 1 . The group 2 patients $(n=72)$ were more likely to have a tumor involving the gastroesophageal (GE) junction $(P=0.005)$, a higher clinical T stage (cT; $P=0.000)$, and a higher clinical $\mathrm{N}$ stage $(P=0.024)$ than the group 1 patients $(n=89)$. In addition, significantly more patients in group II died $(P=0.004)$ and the follow-up period was significantly shorter for group 2 , with a median follow-up of 16.2 months [interquartile range (IQR) 9.2-40.3 months] compared with 23.2 months (IQR 11.8-52.9 months) for group $1(P=0.037)$.

In group 1 and 2 respectively 79.8 and $80.6 \%$ of the patients were able to complete the entire nCRT regimen (Table 2). Of the patients in group 2, 12 (16.7\%) fulfilled two extended criteria, $4(5.6 \%)$ fulfilled three criteria, and 1 (1.4\%) fulfilled four criteria. The presence of two or more extended eligibility criteria within a patient $(n=17)$ versus only one extended criterion $(n=55)$ did not influence the OS $(P=0.642)$ or DFS $(P=0.198)$.

\section{Toxicity and Postoperative Survival}

Table 2 displays the distribution of nCRT toxicity, postoperative complications, and postoperative mortality (30- and 90-day rates) between the two groups. A total of 48 patients $(29.8 \%)$ experienced severe toxicity (grade $\geq 3$ ) or received a blood transfusion. The total toxicity rates did not differ between the two groups $(P=0.117)$, nor did the number of postoperative complications (data shown in Table 2).

Although more patients in group $2(n=7,9.7 \%)$ died within 90 days after surgery than in group $1(n=6,6.7 \%)$, this difference was not significant $(P=0.492)$. In addition, the 30-day postoperative mortality did not differ between the two groups $(P=0.486)$, with a 30 -day mortality rate of $2.2 \%(n=2)$ in group 1 and $4.2 \%(n=3)$ in group 2 .

\section{Overall Survival}

Figure 1 displays the Kaplan-Meier curves with the OS and DFS for both group 1 and 2. The OS differed significantly between the two groups $(P=0.004$ : Fig. 1a), with a median of 37.3 months $(95 \%$ confidence interval [CI] 10.4-64.2 months) in group 1 and 17.2 months (95\% CI 13.8-20.7 months) in group 2. Table 3 displays the 
TABLE 2 Treatment toxicity and complications

\begin{tabular}{|c|c|c|c|}
\hline & $\begin{array}{l}\text { Group } 1 \\
(n=89) \\
n(\%)\end{array}$ & $\begin{array}{l}\text { Group 2 } \\
(n=72) \\
n(\%)\end{array}$ & $P$ value \\
\hline Completed nCRT & $71(79.8)$ & $58(80.6)$ & $0.902^{\mathrm{a}}$ \\
\hline Hematologic toxicity & & & $0.068^{\mathrm{a}}$ \\
\hline \multicolumn{4}{|l|}{ Thrombocytopenia-overall } \\
\hline Not applicable & $26(29.2)$ & $28(38.9)$ & \\
\hline Grade 1 & $54(60.7)$ & $43(59.7)$ & \\
\hline Grade 2 & $8(9.0)$ & $1(1.4)$ & \\
\hline Grade 3 & $1(1.1)$ & $0(0.0)$ & \\
\hline Leukopenia-overall & & & $0.338^{\mathrm{a}}$ \\
\hline Not applicable & $15(16.9)$ & $20(27.8)$ & \\
\hline Grade 1 & $34(38.2)$ & $21(29.2)$ & \\
\hline Grade 2 & $26(29.2)$ & $19(26.4)$ & \\
\hline Grade 3 & $13(14.6)$ & $12(16.7)$ & \\
\hline Grade 4 & $1(1.1)$ & $0(0.0)$ & \\
\hline Blood transfusion & & & $0.417^{\mathrm{a}}$ \\
\hline 0 & $87(97.8)$ & $67(93.1)$ & \\
\hline 1 & $0(0.0)$ & $1(1.4)$ & \\
\hline 2 & $1(1.1)$ & $1(1.4)$ & \\
\hline 3 & $1(1.1)$ & $2(2.8)$ & \\
\hline 4 & $0(0.0)$ & $1(1.4)$ & \\
\hline \multicolumn{4}{|l|}{ Other nCRT complications (grade $\geq 3$ ) } \\
\hline Anemia & $0(0.0)$ & $0(0.0)$ & $\mathrm{NA}^{\mathrm{a}}$ \\
\hline Bleeding & $0(0.0)$ & $1(1.4)$ & $0.203^{\mathrm{a}}$ \\
\hline Nausea & $3(3.4)$ & $4(5.6)$ & $0.501^{\mathrm{a}}$ \\
\hline Fatigue & $1(1.1)$ & $1(1.4)$ & $0.880^{\mathrm{a}}$ \\
\hline Neurotoxic & $0(0.0)$ & $2(2.8)$ & $0.071^{\mathrm{a}}$ \\
\hline Diarrhea & $0(0.0)$ & $1(1.4)$ & $0.203^{\mathrm{a}}$ \\
\hline Esophagitis & $2(2.2)$ & $5(6.9)$ & $0.144^{\mathrm{a}}$ \\
\hline Grade $\geq 3$ or blood transfusion & $22(24.7)$ & $26(36.1)$ & $0.117^{\mathrm{a}}$ \\
\hline \multicolumn{4}{|l|}{ Postoperative complications } \\
\hline Pulmonary (all grades) ${ }^{\mathrm{b}}$ & $49(55.1)$ & $38(52.8)$ & $0.773^{\mathrm{a}}$ \\
\hline Pneumonia & $41(46.1)$ & $28(38.9)$ & $0.360^{\mathrm{a}}$ \\
\hline Respiratory insufficiency & $19(21.3)$ & $13(18.1)$ & $0.602^{\mathrm{a}}$ \\
\hline Pulmonary embolism & $2(2.2)$ & $0(0.0)$ & $0.122^{\mathrm{a}}$ \\
\hline Cardiac (all grades) ${ }^{\mathrm{c}}$ & $26(29.2)$ & $22(30.6)$ & $0.835^{\mathrm{a}}$ \\
\hline Arrhythmia & $25(28.1)$ & $22(30.6)$ & $0.732^{\mathrm{a}}$ \\
\hline Myocardial infarction & $1(1.4)$ & $0(0.0)$ & $0.273^{\mathrm{a}}$ \\
\hline Sepsis & $8(9.0)$ & $6(8.3)$ & $0.883^{\mathrm{a}}$ \\
\hline Postoperative bleeding & $2(2.2)$ & $1(1.4)$ & $0.678^{\mathrm{a}}$ \\
\hline Chylothorax & $11(12.4)$ & $3(4.2)$ & $0.057^{\mathrm{a}}$ \\
\hline Cardiac arrest & $2(2.2)$ & $3(4.2)$ & $0.486^{\mathrm{a}}$ \\
\hline Esophageal anastomotic leak & $8(9.0)$ & $12(16.7)$ & $0.143^{\mathrm{a}}$ \\
\hline Renal failure & $2(2.2)$ & $4(5.6)$ & $0.276^{\mathrm{a}}$ \\
\hline IIeus & $6(6.7)$ & $2(2.8)$ & $0.237^{\mathrm{a}}$ \\
\hline All patients with complications (all grades) & $60(67.4)$ & $50(69.4)$ & $0.783^{\mathrm{a}}$ \\
\hline \multicolumn{4}{|l|}{ Postoperative mortality } \\
\hline 30-day mortality & $2(2.2)$ & $3(4.2)$ & $0.486^{\mathrm{a}}$ \\
\hline
\end{tabular}


TABLE 2 continued

\begin{tabular}{lll}
\hline & $\begin{array}{l}\text { Group 1 } \\
(n=89) \\
n(\%)\end{array}$ & $\begin{array}{l}\text { Group 2 } \\
(n=72) \\
(\%)\end{array}$ \\
\hline 90 -day mortality & $6(6.7)$ & $7(9.7)$ \\
\hline$n C R T$ neoadjuvant chemoradiotherapy, NA not applicable & \\
a Likelihood ratio \\
b Pneumonia, atelectasis, respiratory insufficiency, acute respiratory distress syndrome, pleural effusion, pneumothorax and/or pulmonary \\
embolism \\
c Arrhythmia and/or myocardial infarction
\end{tabular}

extended CROSS criteria and the factors with a $P$ value lower than 0.10 in the univariate analysis. Independent prognostic factors for OS in the multivariate Cox regression analysis were ypN $(P=0.023)$, ypT $(P=0.043)$, and group $2(P=0.008)$. In a multivariate Cox regression analysis that assessed each eligibility criterion separately, only celiac lymph node involvement [hazard ratio (HR) 3.583 ; 95\% CI $1.884-6.814 ; P=0.000$ ] was an independent prognostic factor for OS.

\section{Disease-Free Survival}

The difference in DFS between group 1 and 2 approached significance $(P=0.073$; Fig. $1 \mathrm{~b})$, with a median of 42.5 months (95\% CI 15.7-69.4 months) in group 1 and 18.2 months (95\% CI 7.4-28.9 months) in group 2 . Table 4 displays the extended CROSS criteria and the factors with a $P$ value lower than 0.10 in the univariate analyses, as well as the independent prognostic factors in the multivariate Cox regression analysis for DFS. Gender $(P=0.024)$, LN ratio $(P=0.001)$, squamous cell carcinoma $(P=0.031)$, and group $2(P=0.027)$ were independent prognostic factors for DFS. A closer look at specific subgroups of group 2 with multivariate Cox regression analysis showed that only celiac lymph node metastasis was an independent prognostic factor for DFS (HR 3.741; CI 1.822-7.680; $P=0.000$ ).

\section{Comparison of Survival Between the Extended CROSS and dCRT Reference Group}

Supplementary Table 1 depicts the characteristics of the dCRT and extended CROSS group. The dCRT group $(n=80)$ and the extended CROSS group $(n=72)$ differed in cT stage $(P=0.001)$, $\mathrm{cN}$ stage $(P=0.000)$, squamous cell carcinoma $(P=0.006)$, tumor location $(P=0.001)$, age $(P=0.021)$, and WHO performance status $(P=0.007)$. The patients in the extended CROSS group showed an increased OS $(P=0.010$; Fig. $1 \mathrm{~g})$ with the logrank test but not in the Cox-regression model
(Supplementary Table 2) that contained possible confounders. The number of complications grade $\geq 3 \mathrm{did}$ not differ between the two groups $(P=0.115)$.

\section{DISCUSSION}

Several randomized studies, including the CROSS study, have shown that nCRT increases both OS and DFS for EC patients with locoregional disease compared with surgery alone. ${ }^{1,7}$ Moreover, pathologic complete response rates of approximately $30 \%$ are commonly observed after nCRT. ${ }^{1}$ Extending the original criteria for CROSS nCRT is a logical step to improvement of survival in locally advanced EC.

In this study, we assessed the impact of extended eligibility criteria for nCRT on toxicities, OS, and DFS in these patients. No difference was found in the toxicity rates between the patients in group 1 (original CROSS criteria) and group 2 (extended CROSS criteria). However, the OS and DFS in group 2 were significantly lower in the multivariate Cox regression analysis.

Schrauwen et al. ${ }^{5}(n=116)$ found that the extended inclusion criteria based on tumor length greater than $8 \mathrm{~cm}$ $(n=7)$ and age over 75 years $(n=9)$ had no influence on the complication rates but were prognostic for OS with the log-rank test. However, interpreting these results is difficult due to the low number of patients, the absence of multivariate analysis, and the absence of celiac lymph node metastases in the analysis. 5

The overall rate of toxicity (grade $\geq 3$ ) or blood transfusion was not significantly higher in group $2(24.7 \%)$ than in group $1(36.1 \%)(P=0.117)$. The incidences of severe leukopenia (grade $\geq 3$ ) in group $1(15.7 \%)$ and group 2 $(16.7 \%)$ were somewhat higher than the $6 \%$ in the original CROSS trial but within the range of $3-24 \%$ in the literature. ${ }^{1,8,9}$ Furthermore, the observed rates of thrombocytopenia grade 3 or higher of $1.1 \%$ in group 1 and $0 \%$ in group 2 correspond well with the $1 \%$ rate of thrombocytopenia in the CROSS trial. The 30-day mortality rates in group $1(2.2 \%)$ and group $2(4.2 \%)$ are also comparable 
(a)

Overall Survival

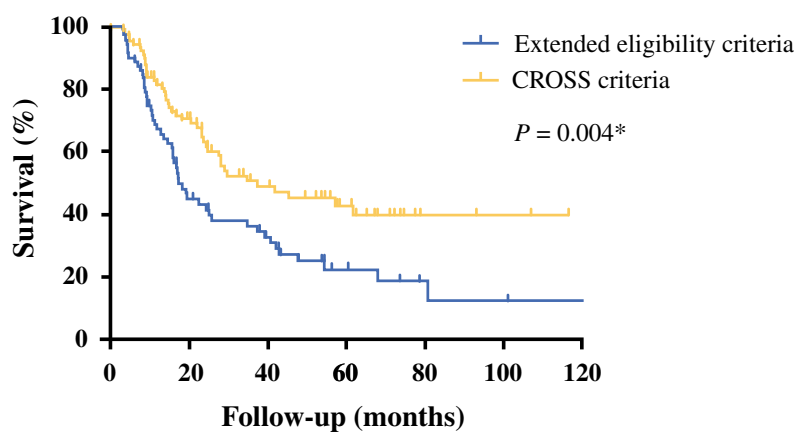

(c)

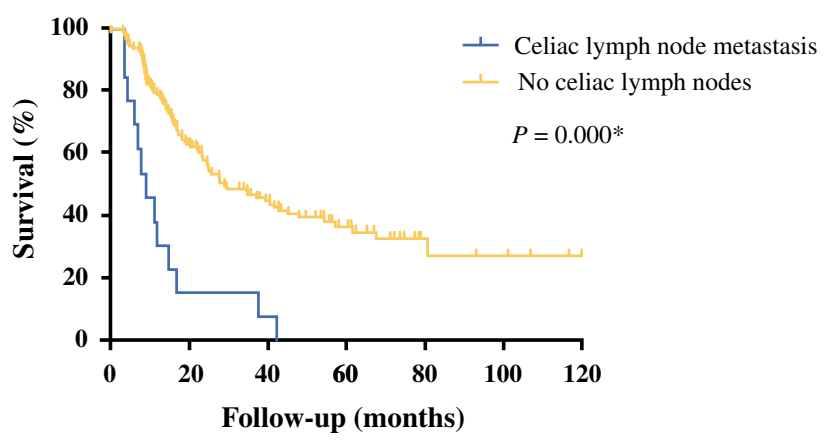

(e)

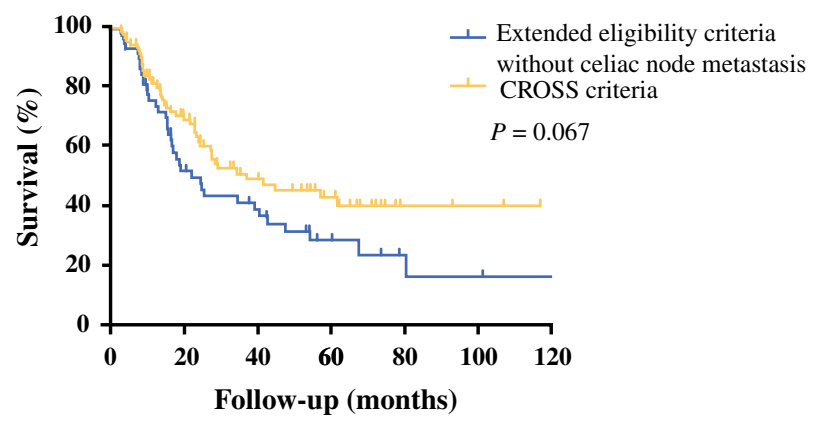

(g)

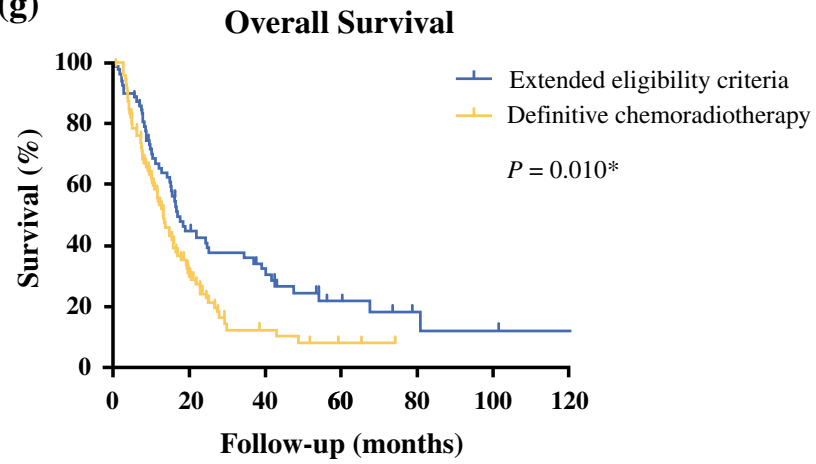

FIG. 1 The overall and disease-free survival in patients that met the original CROSS criteria or the extended CROSS eligibility criteria (a, b), in patients with or without celiac lymph node metastases (c, d), and in patients that met the original CROSS criteria or the extended

\section{(b) Disease-free Survival}

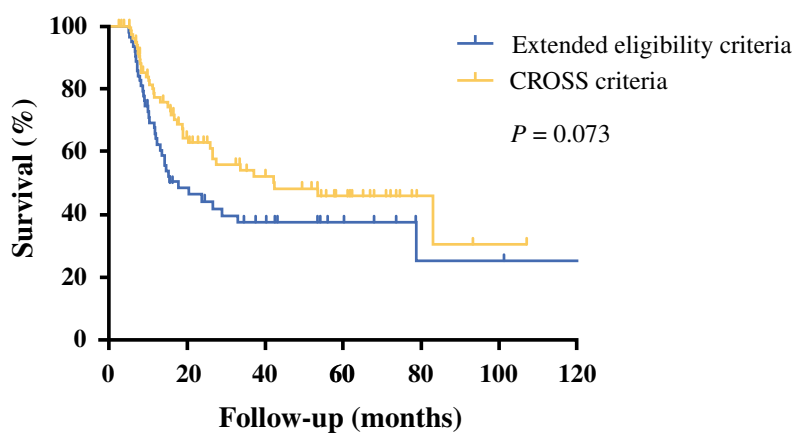

(d)

Disease-free Survival

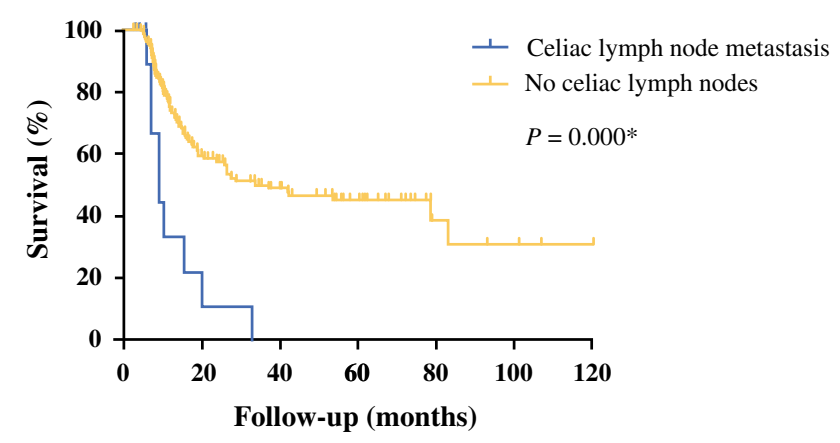

(f)

Disease-free Survival

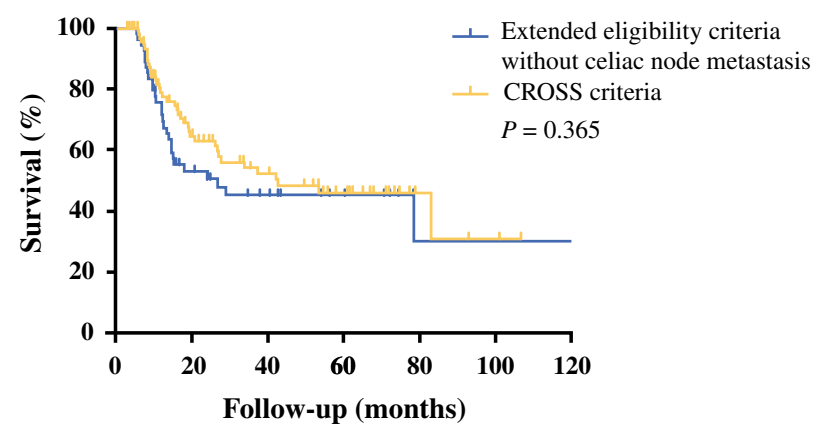

CROSS eligibility criteria without celiac lymph node metastases (e, f). And the overall survival in patients that met the extended CROSS eligibility criteria or patients from a definitive chemoradiotherapy reference group $(\mathbf{g})$ 
TABLE 3 Prognostic factors on uni- and multivariate Cox regression analysis for overall survival

\begin{tabular}{|c|c|c|}
\hline & $\mathrm{HR}(95 \% \mathrm{CI})$ & $P$ value \\
\hline \multicolumn{3}{|l|}{ Univariate analysis } \\
\hline Group 2 & $1.802(1.200-2.707)$ & 0.005 \\
\hline Celiac lymph node metastasis & $3.969(2.188-7.198)$ & 0.000 \\
\hline Cardia growth $2-4 \mathrm{~cm}$ & $1.329(0.721-2.452)$ & 0.362 \\
\hline Length $>8 \mathrm{~cm}$ & $1.217(0.699-2.118)$ & 0.488 \\
\hline Weight loss $>10 \%$ & $1.407(0.892-2.217)$ & 0.142 \\
\hline Squamous cell carcinoma & $0.543(0.295-1.000)$ & 0.050 \\
\hline урт0 & 1.000 & 0.008 \\
\hline урT1 & $0.589(0.254-1.367)$ & \\
\hline урт2 & $1.945(0.974-3.884)$ & \\
\hline урT3 & $1.778(1.019-3.100)$ & \\
\hline ypNO & 1.000 & 0.000 \\
\hline ypN1 & $1.518(0.914-2.522)$ & \\
\hline ypN2 & $2.144(1.158-3.968)$ & \\
\hline ypN3 & $5.024(2.215-11.398)$ & \\
\hline $\mathrm{R} 1$ resection & $3.266(1.543-6.912)$ & 0.002 \\
\hline $\mathrm{LN}$ ratio $(>0.2 \mathrm{LN}+)$ & $2.29(1.437-4.105)$ & 0.001 \\
\hline Perineural growth & $2.076(1.314-3.279)$ & 0.002 \\
\hline Lymphangio-invasion & $1.829(1.125-2.874)$ & 0.015 \\
\hline \multicolumn{3}{|l|}{ Multivariate analysis $^{\mathrm{a}}$} \\
\hline урТ0 & 1.000 & 0.043 \\
\hline урт1 & $0.540(0.224-1.301)$ & \\
\hline урт2 & $1.798(0.854-3.789)$ & \\
\hline урТ3 & $1.294(0.704-2.378)$ & \\
\hline Group 2 & $1.762(1.157-2.685)$ & 0.008 \\
\hline ypNO & 1.000 & 0.023 \\
\hline ypN1 & $1.349(0.805-2.263)$ & \\
\hline ypN2 & $1.896(0.989-3.635)$ & \\
\hline ypN3 & $3.415(1.446-8.064)$ & \\
\hline
\end{tabular}

$H R$ hazard ratio, $C I$ confidence interval, $y p T$ pathologic T stage, $y p N$ pathologic lymph node stage, $L N$ lymph node

${ }^{a}$ Variables with $P<0.10$ in the univariate analysis were included in the multivariate analysis

with the mortality rate of $2 \%$ in the original CROSS study. ${ }^{1}$ Thus, the CROSS nCRT schedule in group 2 is not associated with significantly higher hematologic or nonhematologic toxicity and can be safely applied in the extended patient category.

The 5-year OS of $47 \%$ (median 48.6 months) found in the Dutch randomized CROSS trial is comparable with the $43 \%$ (median 37.3 months) in our group $1 .^{1,2}$ Conversely, the extended criteria group 2 had a remarkably lower 5 -year OS of $23 \%$ (median, 17.2 months). The median survival after noninvasive dCRT, an alternative for patients with considerable comorbidity, is 16-21 months, raising the question whether dCRT is worth considering for the extended patient category. ${ }^{10-13}$ Nevertheless, direct comparison of survival rates in the dCRT and extended CROSS group is not possible because dCRT studies also included irresectable tumors and inoperable patients.

In the included dCRT reference group, we found a significantly lower OS $(P=0.010)$ with the univariate logrank test. However, this test does not correct for baseline differences (gender, cTN stage, tumor localization, tumor length, histology, and age) between the extended nCRT group and the dCRT group. Hence, a multivariate Cox regression analysis containing these confounding variables was performed in which the OS did not differ $(P=0.445)$ between the extended CROSS group and the dCRT group. This suggests that the difference in survival curves might be caused by baseline differences between the groups rather than superiority of nCRT followed by surgery over dCRT. 
TABLE 4 Prognostic factors on uni- and multivariate Cox regression analysis for disease-free survival

\begin{tabular}{|c|c|c|}
\hline & HR (95\% CI) & $P$ value \\
\hline \multicolumn{3}{|l|}{ Univariate analysis } \\
\hline Group 2 & $1.509(0.959-2.375)$ & 0.075 \\
\hline Celiac lymph node metastasis & $3.898(1.923-7.904)$ & 0.000 \\
\hline Cardia growth $2-4 \mathrm{~cm}$ & $1.454(0.742-2.849)$ & 0.275 \\
\hline Length $>8 \mathrm{~cm}$ & $1.103(0.580-2.097)$ & 0.764 \\
\hline Weight loss $>10 \%$ & $1.229(0.720-2.096)$ & 0.450 \\
\hline Female & $0.484(0.255-0.920)$ & 0.027 \\
\hline Squamous cell carcinoma & $0.366(0.167-0.802)$ & 0.012 \\
\hline cT1 and T2 & 1.000 & 0.084 \\
\hline cT3 & $1.961(1.003-3.833)$ & \\
\hline cT4a & $2.894(0.984-8.510)$ & \\
\hline урт0 & 1.000 & 0.023 \\
\hline урТ1 & $1.535(0.636-3.706)$ & \\
\hline урт2 & $3.056(1.298-7.194)$ & \\
\hline урТ3 & $2.632(1.275-5.435)$ & \\
\hline ypNo & 1.000 & 0.001 \\
\hline ypN1 & $1.470(0.812-2.659)$ & \\
\hline ypN2 & $3.060(1.618-5.785)$ & \\
\hline ypN3 & $4.374(1.682-11.375)$ & \\
\hline $\mathrm{R} 1$ resection & $4.389(2.043-9.431)$ & 0.000 \\
\hline $\mathrm{LN}$ ratio $(>0.2 \mathrm{LN}+)$ & $3.106(1.758-5.489)$ & 0.000 \\
\hline Perineural growth & $1.694(0.993-2.890)$ & 0.053 \\
\hline Lymphangio-invasion & $1.940(1.131-3.327)$ & 0.016 \\
\hline \multicolumn{3}{|l|}{ Multivariate analysis $^{\mathrm{a}}$} \\
\hline Female & $0.474(0.248-0.907)$ & 0.024 \\
\hline Squamous cell carcinoma & $0.413(0.185-0.923)$ & 0.031 \\
\hline Group 2 & $1.685(1.061-2.676)$ & 0.027 \\
\hline $\mathrm{LN}$ ratio $(>0.2 \mathrm{LN}+)$ & $2.712(1.524-4.826)$ & 0.001 \\
\hline
\end{tabular}

$H R$ hazard ratio, $C I$ confidence interval, $c T$ clinical T stage, $y p T$ pathologic $\mathrm{T}$ stage, $y p N$ pathologic lymph node stage, $L N$ lymph node PUB1: OK not to spell PET/CT here? Spelling here would be cumbersome

${ }^{\text {a }}$ Variables with $P<0.10$ in the univariate analysis were included in the multivariate analysis

Several studies found a comparable outcome in patients with celiac and regional lymph node metastasis. Celiac lymph node metastases are therefore currently classified as regional lymph nodes $(\mathrm{N}+)$, whereas previous classification systems regarded them as distant (M1a). ${ }^{14-16}$ In the current study, the presence of tumor-positive celiac lymph nodes $(n=13)$ was the only extended eligibility criterion with an independent prognostic value. We compared the survival of patients with celiac lymph node metastases in the extended CROSS group $(n=13)$ with M1a patients in the dCRT group (the latter involving both irresectable higher mediastinal and celiac nodes; $n=15$ ) and found no difference in survival $(P=0.336)$. However, the groups were too small for a solid conclusion. Davies et al. ${ }^{10}$ found that celiac lymph node metastasis (determined by endoscopic ultrasound) was not prognostic for OS after
dCRT, which was confirmed by Gwynne et al. ${ }^{13}$ However, further research seems necessary to elucidate the value of dCRT for patients with celiac lymph node metastasis, probably in a randomized controlled trial or a large retrospective study.

The potential limitations of our study include the small sample size, especially the subgroup of patients with celiac lymph node metastases $(n=13)$. Moreover, two of these patients died within 90 days after surgery, which may have influenced the OS. Another potential weakness is that we included only patients who received surgery, whereas approximately $8 \%$ experience interval metastases between nCRT and surgery. ${ }^{17}$

In conclusion, extension of the original CROSS inclusion criteria for nCRT followed by surgery in EC did not influence the toxicity rate, indicating safe application of the 
CROSS nCRT regimen in the extended patient category. However, the OS in the extended CROSS group was significantly lower than in the standard CROSS group and did not differ significantly from the OS in the dCRT reference group in the multivariate Cox regression analysis. This implies that the additional value of nCRT followed by surgery compared with dCRT in the extended CROSS group might be limited. The findings of this study support further research regarding the strategy to extend the original CROSS criteria for nCRT in patients with locally advanced EC, and should focus more on patients with celiac node metastases.

DISCLOSURE The authors have nothing to disclose.

OPEN ACCESS This article is distributed under the terms of the Creative Commons Attribution 4.0 International License (http:// creativecommons.org/licenses/by/4.0/), which permits unrestricted use, distribution, and reproduction in any medium, provided you give appropriate credit to the original author(s) and the source, provide a link to the Creative Commons license, and indicate if changes were made.

\section{REFERENCES}

1. van Hagen $\mathrm{P}$, Hulshof MC, van Lanschot JJ, et al. Preoperative chemoradiotherapy for esophageal or junctional cancer. $N$ Engl $J$ Med. 2012;366:2074-84.

2. Shapiro J, van Lanschot JJ, Hulshof MC, et al. Neoadjuvant chemoradiotherapy plus surgery versus surgery alone for oesophageal or junctional cancer (CROSS);long-term results of a randomised controlled trial. Lancet Oncol. 2015;16:1090-8.

3. American Joint Committee on Cancer. AJCC cancer staging manual. 6th ed. New York: Springer; 2002.

4. American Joint Committee on Cancer. AJCC cancer staging manual. 7th ed. New York: Springer; 2009.

5. Schrauwen RWM, Bisseling TM, Bonenkamp JJ, Radema SA, Rütten H, Rosman C, et al. Uitkomsten van neoadjuvante chemoradiotherapie gevolgd door slokdarmresectie bij patiënten met een hogere leeftijd of een grotere tumorlengte. NTvO. 2015;12:50-7.
6. Anonymous National Cancer Institute. Common terminology criteria for adverse events. v.3.0 and v.4.0 (CTCAE). 2015. http:// ctep.cancer.gov/protocolDevelopment/electronic_applications/ ctc.htm.

7. Sjoquist KM, Burmeister BH, Smithers BM, et al. Survival after neoadjuvant chemotherapy or chemoradiotherapy for resectable oesophageal carcinoma: an updated meta-analysis. Lancet Oncol. 2011;12:681-92.

8. Blom RL, van Heijl M, Klinkenbijl JH, et al. Neoadjuvant chemoradiotherapy followed by esophagectomy does not increase morbidity in patients over 70. Dis Esophagus. 2013;26:510-16.

9. van Meerten E, Muller K, Tilanus HW, et al. Neoadjuvant concurrent chemoradiation with weekly paclitaxel and carboplatin for patients with oesophageal cancer: a phase II study. $\mathrm{Br} J$ Cancer. 2006;94:1389-94.

10. Davies L, Lewis WG, Arnold DT, et al. Prognostic significance of age in the radical treatment of oesophageal cancer with surgery or chemoradiotherapy: a prospective observational cohort study. Clin Oncol. 2010;22:578-85.

11. Honing J, Smit JK, Muijs CT, et al. A comparison of carboplatin and paclitaxel with cisplatinum and 5-fluorouracil in definitive chemoradiation in esophageal cancer patients. Ann Oncol. 2014;25:638-43.

12. Shao MS, Wong AT, Schwartz D, Weiner JP, Schreiber D. Definitive or preoperative chemoradiation therapy for esophageal cancer: patterns of care and survival outcomes. Ann Thorac Surg. 2016;101:2148-54.

13. Gwynne S, Hurt C, Evans M, Holden C, Vout L, Crosby T. Definitive chemoradiation for oesophageal cancer: a standard of care in patients with non-metastatic oesophageal cancer. Clin Oncol. 2011;23:182-8.

14. Hofstetter W, Correa AM, Bekele N, et al. Proposed modification of nodal status in AJCC esophageal cancer staging system. Ann Thorac Surg. 2007;84:365-73.

15. Talsma K, van Hagen P, Grotenhuis BA, Steyerberg EW, Tilanus HW, van Lanschot JJ, et al. Comparison of the 6th and 7th editions of the UICC-AJCC TNM Classification for Esophageal Cancer. Ann Surg Oncol. 2012;19:2142-8.

16. Sepesi B, Schmidt HE, Lada M, et al. Survival in patients with esophageal adenocarcinoma undergoing trimodality therapy is independent of regional lymph node location. Ann Thorac Surg. 2016;101:1075-81.

17. Stiekema J, Vermeulen D, Vegt E, et al. Detecting interval metastases and response assessment using 18F-FDG PET/CT after neoadjuvant chemoradiotherapy for esophageal cancer. Clin Nucl Med. 2014;39:862-7. 